\title{
Infectious Disease Transmission by Arline Travel
}

\author{
Daniele Provenzano* and Sofy Barocio \\ Department of Biology, University of Texas Rio Grande Valley, USA
}

*Corresponding author: Daniele Provenzano, Department of Biology, University of Texas Rio Grande Valley, Brownsville, TX, U.S.A.

\section{ARTICLE INFO}

Received: 閊 April 27, 2021

Published: 豐 May 19, 2021

Citation: Daniele Provenzano, Sofy Barocio. Infectious Disease Transmission by Arline Travel. Biomed J Sci \& Tech Res 35(5)-2021. BJSTR. MS.ID.005772.

Keywords: Air Travel; Infectious Disease; Global Transmission; Engineering Controls; Pandemic Spread

\begin{abstract}
Improvements in aviation technology have led to considerable growth of domestic and international flights worldwide especially during the past four decades. Commercial flights have increased the movement of and have connected people from virtually all corners of the globe since the end of World War II to exceed 3 billion passengers a year since 2013: a sizable proportion of the global human population. Flight times have decreased considerably from the onset of commercial aviation and the range of airliners has extended substantially. A passenger harboring an infectious agent embarking a flight on one continent can be deplaning on another continent well within half a days' time, in many cases, before manifesting any symptoms of disease. Furthermore, close proximity of passengers, some perhaps immunocompromised, during extended transcontinental flights, combined with relatively low air humidity (10-20\%) and limited air replacements in the pressurized cabin may facilitate exchange of airborne infections. Respiratory pathogens including Mycobacterium tuberculosis, SARS coronavirus, human influenza and parainfluenza viruses and most recently SARS-CoV-2 are most likely candidates to convert aircrafts into atypical, unwitting fomites. Other infectious diseases such as enteric pathogens with an incubation time longer than the duration of any given flight may permit their asymptomatic host to rapidly disseminate an epidemic within or across continents. In this article we review documented precedents, engineering controls on commercial airliners and additional security measures employed on the ground intended to mitigate infectious disease spread and transmission potential through air travel.
\end{abstract}

\section{Introduction}

Following the Wright brothers' first powered flights in 1903, technological advancements in aeronautics have enabled aircraft to overcome distances that would have taken many months or weeks to complete by terrestrial modes in a matter of hours by air [1]. Commercial aircraft carry over 3 billion passengers annually [2] and provide transport not only for cargo and people but also infectious disease. Smallpox, measles, tuberculosis, SARS and seasonal influenza are documented to have been transmitted during commercial flights [3]. Infections may be spread within aircrafts through close contact and by mean of large droplets; airborne spread through small-particle aerosols (as in the case of Severe Acute Respiratory Syndrome [SARS]), through contaminated food or infectious disease vectors (insects, rodents or parasites). Perhaps the greatest concern for global health is the ability of a person with a contagious illness to travel virtually to any part of the world within 24 hours and spread disease across considerable distances [4]. Infected passengers can arrive at their destination during an asymptomatic incubation period and transmit disease without detection [5]. The first decade of the $21^{\text {st }}$ century witnessed the emergence and worldwide spread of two major global epidemics: SARS in 2003 a H1N1 Influenza Virus pandemic of 2009 [6] and most recently the global SARS-CoV-2 pandemic [7]. In all three cases diseases rapidly spread across the globe in a matter of weeks to months, a process linked directly to long-distance traffic routes over which infected individuals dispersed infectious agents $[2,8]$. Other pathogens typically transmitted via person-to-person contact documented to have spread by air travel include Adenovirus, SARSAssociated Coronavirus, Rhinovirus, Human Metapneumovirus, Respiratory Syncytial Virus, Mycoplasma pneumoniae, and Legionella species [4]. 
Despitemany respiratorypathogens being primarily transmitted through direct contact and large droplet spread, few such as Mycoplasma pneumoniae, Influenza Virus, and Measles Virus may also be transmitted through airborne routes [9]. Opportunities for disease spread associated with commercial flight are considerable and include contact with contaminated fomites (counter tops, seats, trays, handrails, toilets, etc.), from close-quarters movement of the passengers while boarding, seating proximity during the flight, or in waiting areas or lines before boarding or after deplaning [10]. Increases in arthropod-borne viruses (Arboviruses) spread have been, in part, attributed to increased air travel harboring mosquito vectors which carry West Nile, Japanese Encephalitis, Venezuelan Equine Encephalitis, Rift Valley Fever, Dengue, Yellow Fever, Chikungunya, and Zika [11]. However, most commonly reported diseases transmitted on aircraft have been spread by the fecal-oral route via contaminated food. A total of 41 in-flight foodborne outbreaks resulting in 11 deaths were documented between 1947 and 1999 [12]. The most commonly implicated culprits are salmonellae, shigellae, and Vibrio cholerae. Although incidence of transmission of infectious diseases by contagious co-passengers remains relatively uncommon [13], International Health Protection Authorities are encouraged to join forces and focus on the problem of epidemic spread via civil aviation because contamination of aircraft by infected passengers is an alarming, documented reality and cause of concern in the absence of World Health Organization (WHO) guidelines for disinfection of pathogenic agents on aircraft [14].

\section{Air Travel}

Air travel appears to have been a dream of the earliest human civilizations as evidenced by the commonly represented winged human archetypes in art and paintings and myths of human flight (notably Icarus) provide evidence of an ancient aspiration to effortlessly cover vast distances with the ease. Early attempts to imitate the natural flight of birds were constrained by limits of human anatomy and physiology. Designs of failed attempts revealed an incomplete understanding of aerodynamics and ineffective power to weight ratios that kept early attempts at flight grounded. Not until the Wright brothers combined their mechanical expertise with an engine capable of delivering sufficient power to provide necessary aerodynamic lift did humans finally launch the era of air travel. The first flights at Kitty Hawk in North Carolina (USA) laid the foundation for technological developments which led to considerable improvements in aerospace engineering and eventually ventures into space. Along the way, air travel presented challenges to the first aeronautic explorers; drafty, unheated, unpressurized flights required flyers to dress warmly to combat cold and carry oxygen to survive the hypoxic atmosphere of high altitudes [1].
Modern commercial passenger cabins, however, are regulated by an environmental system that controls pressurization, temperature, ventilation, and air filtration [12] and provide a comfortable flying experience for the masses. The comforts of modern air travel support a global air transportation network with over three billion passengers travelling between more than 4000 airports on more than 50 million flights a year. This unprecedented mobility effectively connects all corners of the populated globe via airways transporting goods, cargo, and people but also plays an important role in worldwide spread of infectious diseases [15-19] Modern airports, all fewer than 18 hours apart, serve not only as nodes of transport but also transit points for the worldwide spread of disease [20].

\section{Infectious Diseases}

Infectious diseases have played a significant role in the rise and fall of human civilization since prehistoric times. William H. McNeill (1976) elegantly describes the role of human development in the selection and dissemination of infectious disease in Plagues and Peoples. Yersinia pestis, the bacterium responsible for the plague, for example, was able to thrive and prolong its European spread into the $14^{\text {th }}$ and $15^{\text {th }}$ century due to dispersion of asymptomatic carriers trying to escape the foci of disease and unwittingly transmitting the contagion to naïve populations. Likewise, Spanish explorers introduced smallpox chickenpox, and measles to Native American populations who had no immunity against these pathogens with catastrophic consequences. Exposure to these never-before seen infections contributed considerably to the downfall of ancient empires of the New World brought to ruin by a combination of conventional and biological warfare. The conquering Europeans, in return, acquired Treponema pallidum, the spirochete that causes the sexually transmitted disease syphilis, and spread the infection throughout the old World over subsequent centuries causing disfiguring morbidity and death among rulers and peasants alike.

\section{Historical Spread of Infectious Disease by Interconti- nental Travel}

Prior to the advent of industrialization, intercontinental voyages required months at sea. Travelers displaying disease symptoms that could not be addressed by the modest medical means available during a voyage were often dispatched overboard without reaching their destination. This selected for the spread of infectious diseases that could remain asymptomatic for longer times. Ignorance of the germ theory made it impossible to recognize the cause of disease contagion, this assisted infectious agents overcoming long journeys, in some cases, without the realization of the ignorant hosts. Technological advances shortened travel times and brought about the advent of epidemics spreading faster such as the 1918-1920 influenza pandemic which infected 500 million people worldwide with an estimated 50 to 100 million deaths [21]. 
Faster transit times allowed infected passengers to traverse vaster distances spreading contagion not only to fellow travelers before any symptoms appeared but also at their port of arrival. Perhaps not coincidentally, onset of flu symptoms is more rapid than that of the diseases that had spread by mean of transatlantic voyage across the Atlantic during the previous centuries such as the 8 documented cholera pandemics [22].

Contemporary spread of disease by air travel. Air travel has become the principal mean of transcontinental travel over the past century. Commercial aviation became regulated by the Air Commerce Act of 1926 and has since grown to a multibillion-dollar industry that transports an estimate 3.6 billion passengers across the globe annually. The impact of commercial aviation is multifold and ranges from environmental effects resulting in the release of 781 million tons of $\mathrm{CO}_{2}$ released in the atmosphere annually. One other unintended outcome resulting from the growth of air travel is the spread of infectious diseases and the rapid and unprecedented long-range dissemination of microbial agents across the globe. Asymptomatic passengers harboring a pathogen or parasite can easily thwart medical officials at airports of origin and destination; disembark many thousand miles away within a manner of hours or a day and function as a vector for spread of disease. Furthermore, passengers remaining in close contact during long intercontinental journeys are at increased risk of transmission of infectious diseases in the flight cabin. Infectious disease spread by four main routes: direct physical contact, though the air, by mean of inanimate objects (fomites) or contaminated food/water, and by infected arthropod vectors. However, successful spread of contagion to naive hosts depends on numerous additional factors such as virulence of the microorganism, resistance to ambient conditions, length of time outside of host, ability of the organisms to adhere to and survive on inanimate surfaces, duration of exposure, environmental conditions (ventilation, humidity, temperature); and host-specific factors such as general health and immune status [23-26].

\section{Commercial Flight Travel Conditions}

Modern airliners provide a unique environment where susceptible passengers are exposed to each other for prolonged periods of time in close quarters and shared facilities. A full capacity commercial airliner affords among the smallest volumes of air per person of virtually any enclosed public place. At cruising altitudes, the cabin air supply is a mixture of external atmospheric air and recirculated cabin air forced through High Efficiency Particulate Air (HEPA) filters that remove particles $>0.3$ microns. Approximately half of the air in a commercial airplane cabin is drawn from the exterior through the jet engines, run through compressors and fed into the aircrafts air-condition system where it mixes with recirculated cabin air before circulating through HEPA filters. Though the external air supply at altitude is assumed to be sterile, these filters ensure the removal of dust, vapors, bacteria, and fungi.
HEPA filters also effectively capture viral particles spread by droplet nuclei $[24,27]$. Modern aircraft are equipped with environmental control systems that produce laminar (side to side) circulation of cabin air [12]. Air enters the cabin from overhead, circulates across the aircraft and exits the cabin near the floor. Longitudinal (front to back) airflow is limited, effectively giving rise to sections of air flow in the cabin which prevent spread of airborne particles [12]. Despite these controls, passengers remain vulnerable to airborne transmission as evidenced by multiple documented cases of incabin spread of infectious disease.

\section{Measles, An Example of Transmission by Direct Contact}

During typical flight conditions, passengers are exposed to the greatest risk of disease transmission because of high-person density and close proximity [12]. This greatly facilitates disease spread of, for example, measles, because transmission can occur during the earliest (prodromal) stages of illness when a passenger might be unaware of their condition. Measles is a highly contagious viral infection transmitted by direct contact via infectious droplets [28] that has been nearly eradicated from the United States as a result of aggressive vaccination campaigns [12]. However, cases continued to be reported as a result of infected individuals traveling into the US from countries where measles has remained endemic and as a result of failure to adhere to preventive recommendations [29]. Seven cases of secondary measles linked to an index case as a result of in-transit exposure were reported in 1982. In one such case a passenger spread the virus in the flight cabin while five other individuals were infected at a common departure gate [30]. That same year, two passengers were infected by a separate index passenger on a flight from Venezuela to Miami and 8 cases of in-flight transmitted measles were reported during a flight from New York to Tel Aviv in 1994. Between 1996 and 2000, 30\% of measles cases imported into the US were estimated to be from people who travelled while experiencing symptoms of the disease. In June 2005, an unvaccinated traveler was identified as the source of a measles outbreak in Brazil [28]. The index case was originally exposed to measles in the Maldives and during subsequent flights transmitted the disease to two secondary cases, both of whom were unvaccinated [28].

\section{Tuberculosis Spread Through Small Droplets}

Tuberculosis (TB) is a significant cause of mortality and morbidity with millions of new cases reported each year [31]. WHO guidelines indicate that sitting within two rows of an infectious passenger on flights lasting more than 8 hours is sufficient for TB transmission [32]. The United States Centers for Disease Control and Prevention (CDC) conducted investigations of seven index cases that had flown between 1992 and 1994 [9]. Transmission was detected in 2 crew members who had worked in close proximity with an index case for at least 12 hours and 4 passengers who 
were seated in the same cabin section as another index case on a flight lasting longer than 8 hours [9]. These findings support the conclusion that transmission of Mycobacterium tuberculosis on flights is similar to exposure during other activities where prolonged contact with potentially infectious individuals occurs. Though awareness and screening programs have raised awareness of the risk of transmission, TB remains a public health concern and recently made news in Ireland where 24 commercial flights associated with infectious cases of TB were reported between 2011 and 2014 [33].

\section{Airborne Influenza Virus}

Influenza spread mediated by air travel and inflight transmission are well documented [34-36] and likely responsible for ever-mutating strains circumnavigating the globe. The first case was reported in 1979 and resulted in $72 \%$ of all passengers aboard the airline contracting influenza A. An inoperative ventilation system and 3-hour flight delay was likely the cause for the high transmission rate observed. A second study reported 55 cases of transmission in 1989 during a military flight from Puerto Rico to Florida. In 1999, 15 mine workers developed symptoms within 4 days after having been seated within five rows of an index case.

\section{Aerosolized SARS Virus}

In 2003, air travel facilitated the rapid spread of the SARS virus from East Asia to over 25 countries along global airline networks. SARS likely originated in Guangdong Province of the People's Republic of China and was spread by infected travelers worldwide. The disease is believed to be transmitted by aerosolized droplets, but airborne or small droplet transmission is thought to explain the distribution of SARS on commercial airlines [12]. Of the thousands of SARS cases documented during the outbreak in 2003, one reported the introduction of SARS into Vietnam by a businessman flying from China via Hong Kong SAR [31]. Dissemination of the infection led to SARS cases reported in Singapore, Beijing, Canada, Germany, France and other countries with in-flight transmission being the most likely cause of spread [37].

\section{SARS-Cov-2 Pandemic}

On December $31^{\text {st, }} 2019$, the WHO announced the first COVID-19 case as a result of a novel coronavirus identified in a group of patients in Wuhan, Hubei Province in China [38]. The virus spread through human-to-human to other Chinese provinces and countries through infected travelers. In spite of a quarantine imposed on travel in and out of Wuhan on January 23 $3^{\text {rd }}, 2020$ an estimated 5 million residents had been reported to already have left the city [39]. By February 19, 2020 COVID-19 cases began to be reported in 16 countries across the globe suggestive that airline travel is likely to have contributed to the rapid spread of the SARS-CoV-2 virus worldwide [39]. In spite of numerous lockdown measures and travel bans the COVID-19 pandemic continued to spread across continents through 2020 and is still on-going at the time of submission of this report. As of May 2021, 3.25 million deaths have been reported to the WHO worldwide.

\section{Food-Borne Illness}

Reports of meals served by airlines having led to gastroenteritis during flights are not uncommon. The principal culprits have been enteric pathogens including salmonellae, shigellae, and Vibrio cholerae, but other bacteria and viruses have also been documented to cause food-borne outbreaks during $[12,40]$ listed 43 outbreaks of food poisoning associated with air travel between 1947 and 2007. Salmonella was the most commonly identified pathogen transmitted on board commercial flights $[22,41]$. However, instances of gastrointestinal illness caused V. cholerae contaminated food or water consumed by passengers during air travel occasionally surface [41-43]. The Centers for Disease Control attest that virtually all reported cases of cholera in the United States are acquired by air travel from regions where the disease is endemic and therefore imported. The first documented case occurred in 1972 on a flight from London to Sydney with 1 fatality in 47 passengers affected [42]. Furthermore, the South American epidemic of the early 1990s reached the United States in February 1992 when 75 passengers on a flight from Lima Peru to Los Angeles, California contracted the disease from cold seafood salad served on the flight; 10 were hospitalized and one died [43].

African Swine Fever (ASF) is caused by the ASF Virus (ASFV) which is transmitted by direct contact with fluids and excretions from infected animals. Other common means of ASFV infection are the bites of infected ticks, and the indirect contact with various contaminated fomites and pork products, where ASFV remains infectious for long periods. As an example, ASFV infectivity persists more than 1000 days in frozen meat [44]. This long ASFV persistence explains that the introduction of contaminated pork meat or other swine products from international transports has been hypothesized to be the way of introduction in Europe; specifically, to Portugal in 1957, to Cuba in 1971, to Brazil in 1978, Belgium in 1985 [45] and, as recently as 2007 to Georgia [46]. These examples illustrate how long-distance air travel can infect individuals at far distances by not only carrying infected passengers but also by transporting infected food products.

\section{Asymptomatic Carriers}

In January of 2010 Haiti experienced a 7.0 magnitude earthquake followed by $>50$ aftershocks which caused considerable damage to the capital Port-au-Prince and the deaths of an estimated 230,000 people; a total of 3 million Haitians were affected by the earthquake. Within a short time of the earthquake rescue and relief efforts began pouring into the country from all corners of the globe but with moderate success; six months after the quake as much as $98 \%$ of the rubble remained uncleared and thousands of bodies 
buried under debris. In mid-October or 2010 Haiti experienced the onset of perhaps the largest cholera epidemic in recent times; up to date over 818,000 cases and 9,753 deaths were reported by the Haitian government in 2018 and the epidemic has still lingering effects. The gram-negative bacterium Vibrio cholerae was not endemic to the island of Hispaniola as no cholera cases have been reported in modern times giving rise to suspicions that this enteric pathogen had been unwittingly imported from elsewhere. This was confirmed by genomic analysis of the bacteria from patient diarrhea revealing a South Asian origin of the epidemic strain [47].

Further investigations employing an epidemiological approach, not unlike that used by John Snow to pinpoint the origin of a cholera epidemic that ravaged the Soho district of London in 1854 confirmed that the source of the Haiti cholera outbreak upstream of the Artibonite river - a major source of Haitian drinking water [48]. Nepalese UN peacekeeping forces encampment contaminated the river by several means: leaky pipes, waste dumping and an open septic pit near the Artibonite. The soldiers were not tested for cholera although they were flown to Haiti from a region in Nepal where a cholera outbreak was ongoing. Evidently, they were not sufficiently symptomatic to rouse suspicion and were able to board a plane and reach their destination functioning as a vector for disease spread across the globe. This example also reinforces an often-overlooked notion that diseases such as cholera may be harbored in a nearly or fully asymptomatic carrier state by some individuals facilitating dissemination, especially via air travel.

The SARS-CoV-2 is also likely to have spread sizably as a result of asymptomatic carriers through air travel. This is perhaps best illustrated by a study that followed a group of 24 asymptomatic tourists exposed to a hotel manager (who later tested positive for COVID-19) flying from Tel Aviv, Israel to Frankfurt, Germany in March 2020 [49]. While none of the travelers displayed any symptoms or received a diagnosis of COVID-19 before embarking in the 4 hour and 40 minutes flight, subsequent testing for SARSCoV-2 produced 7 positives by Real Time Polymerase Chain Reaction (RT-PCR) and 4 of them became symptomatic during the flight. Furthermore, 7 additional passengers unrelated to the group of 24 reported COVID-19 symptoms within 14 days of travel. While the methodology employed in this study does not rule out alternate explanations, the possibility that in-flight transmission of SARS$\mathrm{CoV}-2$ took place from originally asymptomatic carriers cannot be ruled out and appears likely from the rapid world-wide spread of the COVID-19 pandemic [39].

\section{Vector Borne Disease Transmission}

In addition to human passengers, animals regularly transported on aircraft may harbor infectious diseases or carry infected vectors such as mosquitoes, fleas, ticks and other arthropods. As many as 87 cases of "airport malaria", caused primarily by the protozoan parasite Plasmodium falciparum, occurring in and around airports among people who have not travelled to endemic areas evidence that malaria-carrying mosquitoes are transported by aircraft $[50,51]$. Dengue, Chikungunya and yellow fever, viruses also spread by mosquitoes have also been recognized to be transmitted via aircraft [50,52]. Serotype analysis of thousands of dengue cases in Europe and the US point to successive imports of Asian strains coinciding with increased air travel from the 1960s onwards [52]. Chikungunya virus first appeared on the Kenyan coast in 2004 and subsequently emerged in succession on small islands in the Western Indian Ocean [53]. A massive epidemic followed, affecting an estimated 6.9 million in India that swept eastward to Southeast Asia, with cases documented as far as Italy in 2007 [52].

\section{Management}

Early recognition and appropriate infection control measures can help to mitigate the transmission of infectious agents under the authority of international policies and sovereign laws and regulations. These measures range from issuing travel alerts to quarantine or isolation of passengers at risk. Though airlines may refuse to carry passengers due to health concerns, systematic screening of all passengers is costly, time-consuming, and impractical [54]. Prevention of disease outbreak is best achieved by educating travelers of the risks associated with voyaging when ill and taking precautionary measures such as vaccination when travelling to regions with endemic disease. Good hand-washing hygiene has been proven to reduce the risk of disease transmission and should be promoted during air travel [55]. Body substance isolation practices are standard practice in healthcare and may prove to benefit crew or fellow passengers who are at risk of exposure. Although masks [56] have been proven to be effective in the healthcare setting, their use is not well studied in disease control aboard aircraft. Nevertheless, a mask could be made available for passengers suspected of having infectious diseases such as SARS or COVID-19 and procedures should be in place in the event of the necessity for isolation. Notification of risk exposure is warranted for passengers and crew who have been exposed to infectious disease aboard commercial aircraft. This is typically limited to flights lasting longer than 8 hours and is dependent upon the design of the aircraft, flight origin and destination, and health department recommendations.

\section{Risk Assessment}

Risk assessment is complicated by multiple factors that affect transmission of infectious disease in aircrafts. Investigations of tuberculosis spread on flights provide data that suggest that risk of disease transmission to other passengers is proportional to proximity and length of exposure [9]. However, confounding these criteria are studies that report variations such as one outbreak of SARS were passengers seated as far as seven rows from the source were affected [10,56]. Further complicating risk determination is the role cabin ventilation plays in disease transmission. Proper 
ventilation in confined spaces reduces the concentration of airborne contagion logarithmically $[57,58]$. The laminar flow within the cabin prevents longitudinal spread and combined with frequent air exchange through HEPA filtration limits transmission of contagion from one cabin section to another [12]. However, when ventilation system is not operating optimally, chance of transmission can increase. In-flight passenger movement also affects the risk of disease transmission. The movement of fellow passengers, crew, and that of an index patient can modify exposure risks and influence the risk distribution for transmission events [59]. Combining epidemiological data with mathematical models of proximity and ventilation may assist demonstrating the interrelationship of these factors and how they affect disease transmission [12]. Thus far, such models have demonstrated that the risk of in-flight tuberculosis transmission is reduced by half when ventilation rate is doubled and exponentially reduced when passengers are seated 15 seats from the infectious source [60].

\section{Aircraft Maintenance}

In addition to preventive measures which include public health education, screening, and response policy, commercial airlines have implemented on-ground and in-flight control measures to reduce the risk of transmission. Every aircraft undergoes cleaning based on standard cleaning procedures prior to the next departure [14] Neither aircraft manufacturers nor the WHO have provided standard recommendations for cleaning aircraft [32] or safe disinfection. The absence of standard guidelines leaves room for adaptation of best practices, conclusions from new findings, real-life experiences, and circumstances to best deal with life-threatening diseases [14]. The disinfection of aircraft by vector control prior to landing, vector control around airports, and immunization requirements have been shown to be effective in preventing outbreaks in nonendemic areas. This appears particularly important as sporadic Ebola virus epidemics have emerged recurrently in West Africa over the past decade. Unfortunately, only five countries practice standard disinfection even though International Health Regulations recommend disinfecting and insect removal of all aircraft traveling from countries with vector-borne diseases [61-64].

\section{Conclusion}

Continued growth of global air travel is intrinsically and unescapably linked to an increased risk of infectious disease spread and therefore a contributing factor towards the emergence and dispersal of pandemic disease. It is impossible to predict what infectious agent will cause the next pandemic, but it is likely that air travel will contribute to its spread. Social mitigation strategies are difficult to implement without legislating unenforceable rules that infringe on personal freedoms at several levels while continuous ramping up of engineering controls is costly and challenging to deploy. Business can increasingly be transacted through real-time on-line transmission as the emergence of internet-based video- transmission platforms has demonstrated during the COVID-19 pandemic. Pre-travel health screens for common diseases in endemic regions would be reasonable to implement and would alleviate spread of numerous infectious agents. Practices that include the consumption of bush meat, handling of wild-caught animals, the illicit trade of pets and other animal parts represent the potential origins of a wide range of emerging infectious agents can only be effectively halted through public outreach and education campaigns.

Therefore, the most effective strategy in limiting the spread of infectious agents through air travel and other means will entail sensibilizing and educating the general public about health risks associated with travel, on the emergence of infectious agents and personal measures to be taken to prevent acquisition of microbial agents. The challenge of the $21^{\text {st }}$ century to bridge the ever-growing knowledge gap between the continuously expanding technological developments and the still swelling global population of end users of these technologies remains considerable. Engineering, biology, chemistry, physics, electronics, informatics and numerous other sub-disciplines continue to build on previous discoveries and breakthroughs while global educational efforts fragment and partition this massive knowledge bank into small units to meet employment needs. An educational emphasis on holistic understanding that allows students and the population at large to synthesize and analyze information received through an enormous flood of broadcasts through the internet in a manner will help our civilization to ameliorate personal decision making and improve the human condition as a whole.

\section{Conflict of Interest}

The authors have no conflict of interest to declare.

\section{Acknowledgements}

Parts of this work were conducted in partial fulfillment of S.B.'s Masters of Science in Biology at University of Texas Rio Grande Valley. D.P. is supported by National Institutes of Health grant R15AI137972.

\section{References}

1. Budd LCS (2011) On being aeromobile: Airline passengers and the affective experiences of flight. Journal of Transport Geography 19(5): $1010-1016$

2. Woolley-Meza O, Thiemann C, Grady D, Lee JJ, Seebens H, et al. (2011) Complexity in human transportation networks: A comparative analysis of worldwide air transportation and global cargo-ship movements. The European Physical Journal 84(4): 589-600.

3. Wagner BG, Coburn BJ, Blower S (2009) Calculating the potential for within-flight transmission of influenza A (H1N1). BMC Medicine 7: 81.

4. Pavia AT (2007) Germs on a Plane: Aircraft, International Travel, and the Global Spread of Disease. The Journal of Infectious Diseases 195(5): 621-622.

5. Leder K, Newman D (2005) Respiratory infections during air travel. Internal Medicine Journal 35(1): 50-55. 
6. Balcan D, Hu H, Goncalves B, Bajardi P, Poletto C, et al. (2009). Seasonal transmission potential and activity peaks of the new influenza $A$ (H1N1): a Monte Carlo likelihood analysis based on human mobility. BMC Medicine 7: 45.

7. Cucinotta D, Vanelli M (2020) WHO Declares COVID-19 a Pandemic. Acta Biomedica 91(1): 157-160.

8. Oztig LI, Askin OE (2020) Human mobility and coronavirus disease 2019 (COVID-19): a negative binomial regression analysis. (2020) Public Health 185: 364-367.

9. Raviglione M, Martinez L (2008) Tuberculosis and air travel guidelines for prevention and control Third Edition. World Health Organization.

10. Olsen SJ, Chang HL, Cheung TY, Tang AF, Fisk TL, et al. (2003). Transmission of the Severe Acute Respiratory Syndrome on Aircraft. The New England Journal of Medicine 349(25): 2416-2422.

11. Weaver SC, Charlier C, Vasilakis N, Lecuit M (2018) Zika, Chikungunya, and other emerging vector-borne viral diseases. Annual Review of Medicine 69: 395-408.

12. Mangili A, Gendreau MA (2005) Transmission of infectious diseases during commercial air travel. The Lancet 365(9463): 989-996.

13. Walter G, Goetsch U, Diel R, Doerr HW, Gottschalk R (2009) Screening for infectious diseases at international airports: the Frankfurt model. Aviation, Space and Environmental Medicine 80(7): 595-600.

14. Klaus J, Gnirs P, Hölterhoff S, Wirtz A, Jeglitza M, et al. (2016) Disinfection of aircraft. Bundesgesundheitsblatt - Gesundheitsforschung - Gesundheitsschutz 59: 1544-1548.

15. Avila M, Said N, Ojcius DM (2008) The book reopened on infectious diseases. Microbes and Infection 10: 1-6.

16. Cliff A, Haggett P (1995) Disease implications of global change. In R. J. Johnston, P. J. Taylor, \& M. J.Watts (Eds.), Geographies of global change remapping the world in the late twentieth century (pp. 206-223). Oxford: Blackwell, UK.

17. Colizza V, Barrat A, Barthelemy M, Vespignani A (2006) The role of the airline transportation network in the prediction and predictability of global epidemics. Proceedings of the National Academy of Sciences USA 103(7): 2015-2020.

18. Tatem AJ, Hay SI (2007) Climatic similarity and biological exchange in the worldwide airline transportation network. Proceedings of the Royal Society B: Biological Sciences 274(1617): 1489-1496.

19. Tatem AJ, Hay SI, Rogers DJ (2006) Global traffic and disease vector dispersal. Proceedings of the National Academy of Sciences USA 103(16): 6242-6247.

20. Budd LCS, Bell M, Brown T (2009) Of plagues, planes and politics: Controlling the global spread of infectious diseases by air. Political Geography 28: 426-435.

21. Johnson NP, Mueller J (2002) Updating the accounts: global mortality of the 19181920 "Spanish" influenza pandemic. Bulletin of the History of Medicine 76(1): 105-115.

22. Tauxe RV, Tormey MP, Mascola L, Hargrett-Bean NT, Blake PA (1987) Salmonellosis outbreak on transatlantic flights; foodborne illness on aircraft: 1974-1984. American Journal of Epidemiology 125(1): 150157.

23. (1998) World Health Organization 1998. Tuberculosis and air travel: guidelines for prevention and control.

24. (2002) National Research Council 2002. The airline cabin environment and the health of passengers The National Academic Press.

25. (2000) Select Committee on Science and Technology 2000. Air Travel and Health: Fifth report. London: UK House of Lords.
26. Nagda NL, Fortmann RC, Koontz MD, Baker SR, Ginevan ME (1989) Airliner cabin environment: contaminant measurements, health risks, and mitigation options. D0T-P-15-89-5. NTIS/PB91-159384. Prepared by GEOMET Technologies, Germantown, MD, for the U.S. Department of Transportation, Washington DC.

27. Pall Corporation (1998) Pall cabin air filters. Clearwater, FL: Pall Corporation.

28. Ribeiro de Barros F, Danovaro-Holliday MC, Toscano C, Segatto TM, Vicari A, et al. (2006) Measles transmission during commercial air travel in Brazil. Journal of Clinical Virology 36(3): 235-236.

29. Nelson K, Marienau K, Schembri C, Redd S (2013) Measles transmission during air travel, United States, December 1, 2008-December 31, 2011. Travel Medicine and Infectious Disease 11(2): 81-89.

30. Amler RW, Bloch AB, Orenstein WA, Bart KJ, Turner PM Jr, et al. (1982). Imported measles in the United States. JAMA 248: 2129-2133.

31. Leditschke J, Rose T, Cordner S, Woodford N, Pollanen M (2015) The development of a protocol for post-mortem management of Ebola virus disease in the setting of developed countries. Forensic Science, Medicine, and Pathology 11(2): 262-267.

32. Kenyon T, Valway S, Ihle W, Onorato I, Castro K (1996) Transmission of multidrug-resistant Mycobacterium tuberculosis during a long airplane flight. The New England Journal of Medicine 334(15): 933-938.

33. Flanagan P, O’donnell J, Mereckiene J, O'flanagan D (2016) Tuberculosis contact investigations associated with air travel in Ireland, September 2011 to November 2014. Eurosurveillance 21(40): 30358.

34. Sato K, Morishita T, Nobusawa E, Suzuki Y, Miyazaki Y, et al. (2000). Surveillance of influenza viruses isolated from travelers at Nagoya international airport. Epidemiology and Infection 124(3): 507-514.

35. Perz JF, Craig AS, Schaffner W (2001) Mixed outbreak of parainfluenza type 1 and influenza $B$ associated with tourism and air travel. International Journal of Infectious Disease 5(4): 189-191.

36. Laurel VL, DeWitt CC, Geddie YA, Yip MC, Dolan DM, et al. (2001) An outbreak of influenza A caused by imported virus in the United States, July 1999. Clinical Infectious Diseases 32(11): 1639-1642.

37. Desenclos JC, van der Werf S, Bonmarin I, Levy-Bruhl D, Yazdanpanah Y, et al. (2004). Introduction of SARS in France, March-April 2003. Emerging Infectious Diseases 10(2):195-200.

38. Huang C, Wang Y, Li X, Ren L, Zhao J, et al. (2020) Clinical features of patients infected with 2019 novel coronavirus in Wuhan, China. Lancet 395(10223): 497-506.

39. Luo G, McHenry ML, Letterio JJ (2020) Estimating the prevalence and risk of COVID-19 among international travelers and evacuees of Wuhan through modeling and case reports. PLOS ONE 15(6): e0234955

40. McMullan R, Edwards PJ, Kelly MJ, Millar BC, Rooney PJ et al. (2007). Food-poisoning and commercial air travel. Travel Medicine and Infectious Disease 5(5): 276-286.

41. Hatakka M (2000) Hygienic quality of foods served on aircraft. Helsinki: University of Helsinki, Academic Dissertation.

42. Sutton RGA (1974) An outbreak of cholera in Australia due to food served in flight on an international aircraft. Journal of Hygiene 72(3): 441-451.

43. Eberhart-Phillips J, Besser RE, Tormey MP, Koo D, Feikin D, et al. (1996). An outbreak of cholera from food served on an international aircraft. Epidemiology and Infection 116(1): 9-13

44. Adkin A, Coburn H, England T, Hall S, Hartnett E, et al. (2004) Risk assessment for the illegal import of contaminated meat and meat products into Great Britain and the subsequent exposure of GB livestock (IIRA): foot and mouth disease (FMD), classical swine fever (CSF), 
African swine fever (ASF), swine vesicular disease (SVD). New Haw: Veterinary Laboratories Agency.

45. Mur L, Martínez-López B, Sánchez-Vizcaíno J (2012) Risk of African swine fever introduction into the European Union through transportassociated routes: Returning trucks and waste from international ships and planes. BMC Veterinary Research 30(8): 149.

46. Beltran-Alcrudo D, Lubroth J, Depner K, De la Roque S (2008) African swine fever in the Caucasus. EMPRES Watch: 1-8.

47. Chin CS, Sorenson J, Harris JB, Robins WP, Charles RC, et al. (2011) The origin of the Haitian cholera outbreak strain. New England Journal of Medicine 364(1): 33-42

48. Frerichs R, Keim P, Barrais R, Piarroux R (2012) Nepalese origin of cholera epidemic in Haiti. Clinical Microbiology and Infection 18(6): 158-163.

49. Hoehl S, Karaca O, Kohmer N, Westhaus S, Graf J, et al. (2020) Assessment of SARS-CoV-2 Transmission on an International Flight and Among a Tourist Group. JAMA Network Open 3(8): e2018044.

50. Gratz N, Steffen R, Cocksedge W (2000) Why aircraft disinfection? Bulletin World Health Organization 78: 995-1004.

51. Van den Ende J, Lynen L, Elsen P, Colebunders R, Demey H, et al. (1998) A cluster of airport malaria in Belgium in 1995. Acta Clinica Belgica 53(4): 259-263.

52. Institute of Medicine (2010) Infectious Disease Movement in a Borderless World: Workshop Summary. The National Academy Press.

53. Charrel RN, de Lamballiere X, Raoult D (2007) Chikungunya outbreaks the globalization of vector-borne diseases. The New England Journal of Medicine 356(8): 769-771.

54. Air Carrier Access Act of 198614 C.F.R. Part 382. (1986) Nondiscrimination on the basis of handicap in air travel. 49 USC 41702

\section{ISSN: 2574-1241}

DOI: 10.26717/BJSTR.2021.35.005772

Daniele Provenzano. Biomed J Sci \& Tech Res

This work is licensed under Creative Commons Attribution 4.0 License

Submission Link: https://biomedres.us/submit-manuscript.php
55. Centers for Disease Control and Prevention (2002) Guidelines for hand hygiene in health care settings. Morbidity Mortality Weekly Reports 51(16): $1-44$

56. World Health Organization (2003) Consensus document on the epidemiology of severe acute respiratory syndrome (SARS).

57. Nardell E, Keegan J, Cheney S, Etkind SC (1991) Airborne infection: theoretical limits of protection achievable by building ventilation. The American Review of Respiratory Disease 144(2): 302-306.

58. Riley R, Nardell E (1989) Clearing the air. The American Review of Respiratory Disease 139(5): 1286-1294.

59. Han Z, To GN, Fu SC, Chao C, Weng W, et al. (2014) Effect of human movement on airborne disease transmission in an airplane cabin: Study using numerical modeling and quantitative risk analysis. BMC Infectious Diseases $14: 434$

60. Ko G, Thompson KM, Nardell EA (2004) Estimation of tuberculosis risk on a commercial airliner. Risk Analysis 24(2): 379-388.

61. Blake PA (1994) Historical perspectives on pandemic cholera, "in Vibrio cholerae and Cholera: Molecular to Global Perspectives (Eds.), LK Wachsmuth, PA Blake, and O Olsvic (Washington, DC: ASM Press): 292295.

62. Budd LCS (2008) Pests on a plane. Airports and the fight against infectious disease. Airports of the World 18: 48-53.

63. Centers for Disease Control and Prevention (1983) Interstate importation of measles following transmission in an airport-California, Washington 1982. Morbidity Mortality Weekly Reports 32(210): 215216.

64. McNeill WH (1977) Plagues and Peoples, Garden City, N.Y. Anchor Press, USA.

$\begin{array}{ll}\text { BIOMEDICAL } & \text { Assets of Publishing with us } \\ \text { RESEARCHES } & \text { - Global archiving of articles } \\ \text { - Immediate, unrestricted online access }\end{array}$

